\title{
Corrosion and Structural characterization of electrodeposited Hydroxyapatite to specify optimum deposition conditions
}

\author{
Mustafa Sh. Alhilfi*Aqeel F.Hasan** JamalF. Hamodi** \\ *Physics department, College of education-Almustansiriya University- Iraq. \\ **Directorate of Materials Research, Ministry of Science \& Technology-Iraq.
}

\begin{abstract}
Hydroxyapatite (HA) is most important biomaterial which is used as coating layer on implants to speedup bone ingrowth.Cathodic electrodepositionprocess was used to coatTi-6Al-4V alloy with HA. Thechemical solution consists from $\mathrm{Ca}\left(\mathrm{NO}_{3}\right)_{2},\left(\mathrm{NH}_{4}\right)_{2} \mathrm{HPO}_{4}$ and $\mathrm{Na}\left(\mathrm{NO}_{3}\right)_{2}$. Different deposition conditions including applied voltage, deposited time, $\mathrm{PH}$ value and temperature of chemical solution were investigated to obtain ideal coating with best structure and good corrosion parameters. X-ray diffraction (XRD),Scanning electron microscope (SEM) andPotentiodynamic polarization measurements were exploitto characterize structure and corrosion parameters of deposited layers. Under our conditions, best corrosion parameters were obtained when applied voltage 9volt,deposited time 30 minute, $\mathrm{PH}$ value 5.5 and solution temperature $25^{\circ} \mathrm{C}$.
\end{abstract}

Keywords: - Electrodeposition, Hydroxyapatite,Ti-6Al-4V alloy, deposition conditions and corrosion parameters.

\section{INTRODUCTION}

The structure of an implant's coating can significantly affects its physical and chemical properties, and eventuallyits clinical performance.In order to get accelerated osseointegration,Ti-6Al-4V alloy a widely used medical alloy clinicallyis coated with HA a very biocompatible material.Implants bioactivity including corrosion resistance can be improved by HA deposition on it ${ }^{[1]}$. HA cannot replace a failed bone alone because of its bad mechanical properties ${ }^{[2]}$; so many methods ${ }^{[3-5]}$ were utilized to deposit this active biomaterial on Tialloys.One of these methods is electro deposition method, it is low cost, uncomplicated operation and there arechances to cover irregular shapesurfaces ${ }^{[6]}$.Thestructure of the deposited coatings can be controlled by changing thecomposition, $\mathrm{pH}$ and temperature of the electrolyte, as well as theapplied potential or current density .Electrodeposition of HA is based on cathodicreactions composed of two steps of oxygenreduction to produce hydroxyl ions followed byprecipitation of calcium phosphates underalkaline condition on the surface. Whilecrystallization by itself composed of nucleationand growth, controlling electrodepositionparameters can control the microstructure andcomposition of HA deposits ${ }^{[7]}$. At best of our knowledge there is no complete investigation concern with finding the optimum of all following deposition parameters: applied voltage, $\mathrm{PH}$ of chemical solution, the temperature of chemical solution and deposition time. In this contribution the effects of the variation of all these parameters on structure and corrosion parameters were studied.

\section{1- Sample preparation:}

\section{EXPERIMENTAL PART}

Circular samples were cut from Ti-6Al-4V rod of $15 \mathrm{~mm}$ diameter, using wire cut machine.Silicon Carbide(SiC) papers (500-1000 grit) were used to polish the samples. For the purpose of removing debris and contamination from thesamples, ultrasonic cleaningbath (Sonomatic/170-2-T80, Germany) with acetone was carried out for 20 minute. This cleaning process was repeated twiceand all samples were dried at $100^{\circ} \mathrm{C}$.

\section{2- Chemical solution preparation:}

The essential chemical solution (ECHS), which is used for all experiments in this contribution, consists from 6.6 $\mathrm{gm} / \mathrm{l} \mathrm{Ca}\left(\mathrm{NO}_{3}\right)_{2}, 3.56 \mathrm{gm} / \mathrm{l}\left(\mathrm{NH}_{4}\right)_{2} \mathrm{HPO}_{4}$ and $8.5 \mathrm{gm} / 1 \mathrm{Na}\left(\mathrm{NO}_{3}\right)_{2}$.

\section{3- Experiments of choosing optimum deposition voltage:}

To get the best deposition voltage, (ECHS) was used with fixation of PH at 5.5.Polished Ti-6Al-4V samples were put inside chemical cell as cathode, another Ti6Al-4V sample with the same dimensions represents the anode. The voltages between anode and cathode were changed for three runs taking the following values 5,7 and 9 volt respectively. Each voltage value was applied for one hour at $25^{\circ} \mathrm{C}$. After deposition processfor this and following experiments, the samples were taken out from ECHS and immersed inside $1 \mathrm{M} \mathrm{NaOH}$ solution for one 
hour at ambient conditions. The samples were put inside tube furnace at $400^{\circ} \mathrm{C}$ for one hour, the normal air surrounded the samples during heat treatment.

\section{4- Experiments of choosing optimumPH value:}

To get the best PH value, (ECHS) was used with fixation of voltage at 9 volt. Three experiments with three different $\mathrm{PH}$ values $\left(4.5,5.5\right.$ and 6.5) were used for one hour at $25^{\circ} \mathrm{C}$.

\section{5- Experiments of choosing optimumtemperature degree:}

To get the best temperature degree, (ECHS) was used with fixation of voltage at 9 volt and PH at 5.5. Three experiments with three different temperature degrees $\left(25,40\right.$ and $\left.60^{\circ} \mathrm{C}\right)$ were used for one hour.

\section{6- Experiments of choosing optimumdeposition time:}

To get the best deposition time, (ECHS) was used with fixation of voltage at 9 volt , PH at 5.5 and temperature at $25^{\circ} \mathrm{C}$. Three experiments with three different deposition times (30, 40 and 60 minutes) were used.

\section{7-Samples characterization:}

Optical microscope (Nikon Eclipse ME 600L/441002, Japan) was used to evaluate the surface modification at micrometer scale. Scanning electron microscope (VEGA II SBH MS 12) was used to explore the surface topology. Structural analysis for the modified surfaces was carried out using X- ray diffraction (SHIMADZU, XRD-6000, Japan.)Annealing process was done using tube furnace (Carbolite Type MTF 12/38A BAMFORD England). The electrochemical measurements were carried out using potentiostat / galvanostat (PARASATE 2273, Princeton Applied Research) provided with electrochemical interface controlled by commercial POWER SUITE software.The corrosion measurements were done for the specimens under equilibrated conditions in simulated body fluid (SBF) as can be seen from itsconstituents in Table 1.

Table (1) thecompositions of SBF

\begin{tabular}{|c|c|c|}
\hline Order & Reagent & Weight(gm/l) \\
\hline 1 & $\mathrm{NaCl}$ & 6.800 \\
\hline 2 & $\mathrm{KCl}$ & 0.400 \\
\hline 3 & $\mathrm{CaCl}$ & 0.200 \\
\hline 4 & $\mathrm{NaHCO}_{3}$ & 2.200 \\
\hline 5 & $\mathrm{Na}_{2} \mathrm{HPO}_{4}$ & 0.126 \\
\hline 6 & $\mathrm{NaH}_{2} \mathrm{PO}_{4}$ & 0.026 \\
\hline 7 & $\mathrm{MgSO}_{4}$ & 0.100 \\
\hline
\end{tabular}

\section{RESULTS AND DISCUSSION:}

1-Results and discussion ofoptimum deposition voltage:

\section{A- Structure characterization:}

Figure 1 shows XRD patterns ofuncoated specimen and samples after electrochemical deposition and treatment in $\mathrm{NaOH}$ solution at different applied voltage. It shows that the reflections can be indexed to the standard $\mathrm{HA}, \mathrm{CaPO}_{3}(\mathrm{OH})$ and Ti patterns. The appearance of Ti reflections indicates that the coating deposited on the Ti

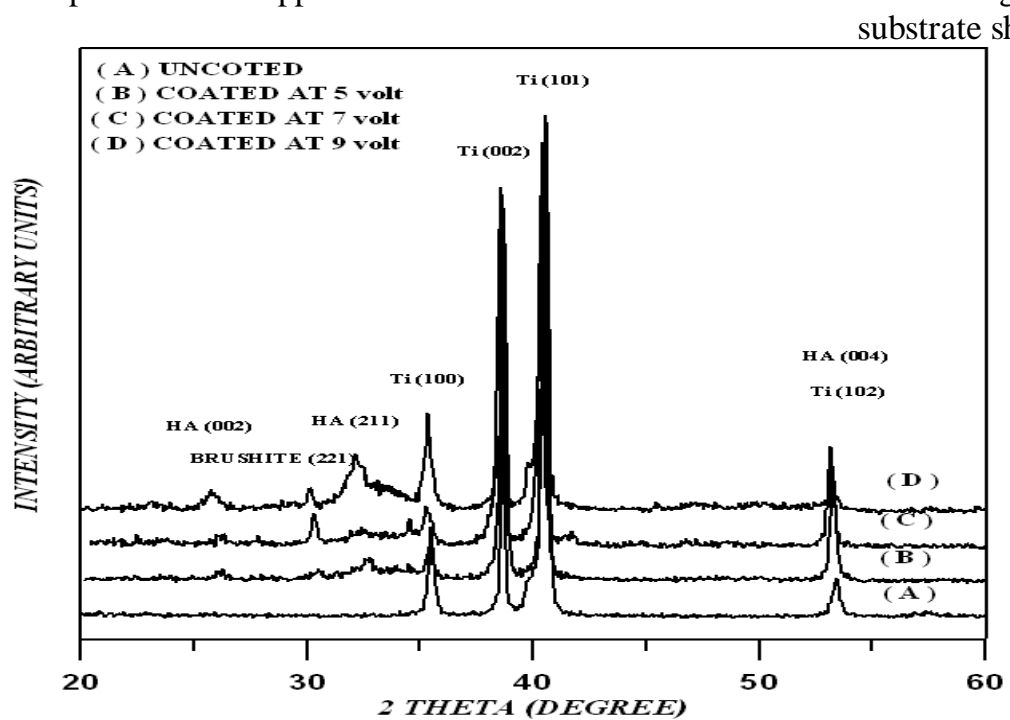

Figure (1) XRD patterns of Ti-6Al-4V samples after deposition process at different applied voltages between anode and cathode. 
Figure 1 illustrates the increasing of HA peaks,(211) and (002) intensities with applied voltage. Increasing voltage enhance decomposition of water at the cathode and then increasing $\mathrm{OH}^{-}$concentration which play important role in production of $\mathrm{HPO}_{4}^{-2}$ which is necessary factor of subsequent chemical reactions of production HA Phase. ${ }^{[9]}$

Another $\mathrm{CaP}$ Phase appears in this pattern, this Phase is Brushite $\left(\mathrm{CaPO}_{3}(\mathrm{OH})\right)$.It is demonstrated that Brushite coatings may be converted to HA by treatment in alkaline solutions. Because of the large sizes of the precursor crystals, complete transformation of Brushite to HA may not be achieved and thus the coating obtained by this route may contain impurities such as amorphous calcium Phosphate ${ }^{[\mathbf{1 0 ]}}$.

\section{B- Corrosion studies:}

\section{I-Open circuit potential-time measurements}

The open circuit potential is a parameter which indicates the thermodynamically tendency of a material to electrochemical oxidation in a corrosive medium. After a period of immersion it stabilizes around a stationary value. This potential may vary with time because changes in the nature of the surface of the electrode occur (oxidation, formation of the passive layer or immunity). The open circuit potential is used as a criterion for the corrosion behavior.The open circuit potential (OCP) - time plots for uncoated and HA coated Ti-6Al-4V at various deposition voltages are shown in Figure2.The OCP curves of the all samples show increasing in the noble direction with time, until a steady states potential are almost attained.

The time required to attain steady state was considerably shorter for a samples coated with 5 and 9 volts than for sample coated with 7 volt. In the case of coated samples with 5 and 9 volts, the OCP werefound to be shifted considerably more in the noble direction compared to the uncoated sample. This shift of OCP and its saturation as a stable potential indicates the formation of a stable HA/Ti interface. ${ }^{[11]}$

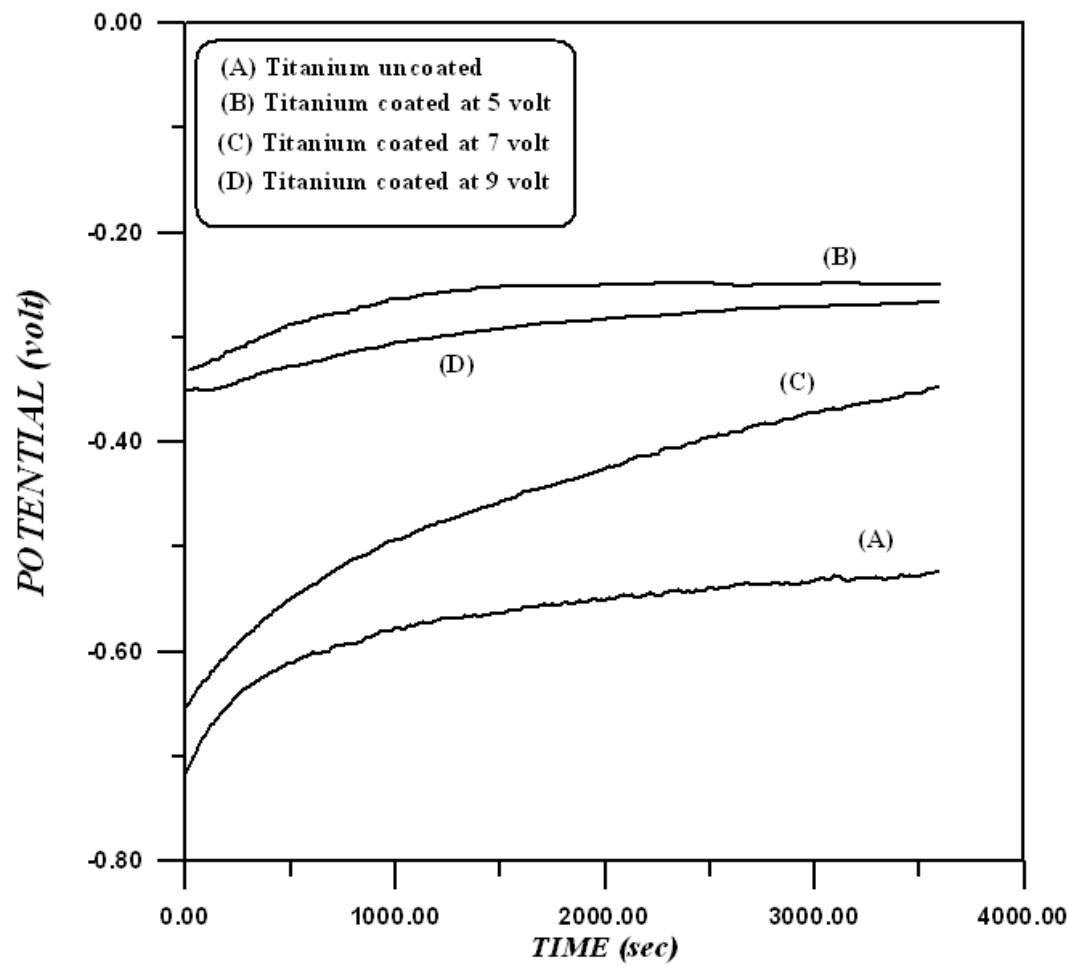

Figure(2)Open circuit potential in SBF solution versus time plots for a uncoated and HA coated Ti-6Al-4V

\section{II-Potentiodynamic polarisation studies}

As the OCP measurements and their evolution with immersion time reveal only a tendency to corrosion or to passivation of the surface material, the evaluation of the corrosion rate requires the analysis of potentiodynamic polarization curves. Figure(3) illustrates Tafel plots for uncoated and HA coated samples with different applied voltage. 


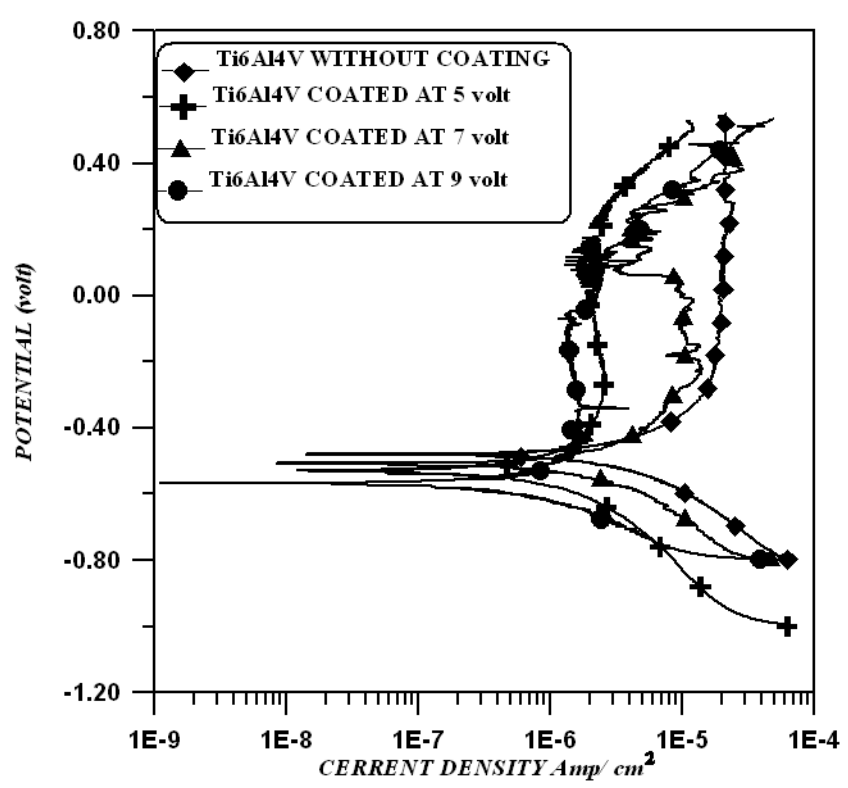

Figure (3) Tafel plots for uncoated and coated Ti-6Al-4V alloy with various applied voltage. The electrochemical parameters obtained by Potentiodynamic polarisation are presented in Table 2.

Table(2)Electrochemical parameters for coated and uncoated Ti alloy at various applied voltage.

\begin{tabular}{|c|c|c|c|}
\hline Applied Voltage (volt) & $\begin{array}{l}\mathbf{E}_{\text {CoRR. }} \\
(\text { volt })\end{array}$ & $\begin{array}{c}\mathbf{I}_{\text {CORR. }} \\
(\mu \mathrm{A})\end{array}$ & $\begin{array}{c}\text { Corrosion Rate } \\
(\mathbf{m m p y}) * 10^{-3}\end{array}$ \\
\hline Uncoated & $-\mathbf{0 . 4 8 2}$ & $\mathbf{1 . 1 2 8}$ & $\mathbf{1 0 . 2 3}$ \\
\hline 5 & -0.52 & $\mathbf{0 . 8 9 6 6}$ & $\mathbf{8 . 1 3 3}$ \\
\hline 7 & -0.571 & $\mathbf{0 . 7 5 3 7}$ & $\mathbf{6 . 8 3 6}$ \\
\hline 9 & -0.571 & $\mathbf{0 . 1 4 6 5}$ & $\mathbf{1 . 3 2 9}$ \\
\hline
\end{tabular}

From Figure 3 and Table 2, it can be observed the improvements of three important corrosion parameters with increasing applied voltage between anode and cathode: Passive current, Corrosion current ( $\mathrm{I}_{\mathrm{CORR}}$ ) and Corrosion rate. Passivation regions are shifted towards smaller current densities with increasing applied voltage; this refers to reinforcement of a passive layer with increasing voltage. Comparison between Corrosion current values of untreated and coated sample at 9 volt shows that the corrosion progress was more than ten times faster on untreated than on coated sample. Also Corrosion rate of uncoated sample is reduced to about its tenth value when applied voltage increased to 9 volt. This refers to the success of electrochemical HA deposition with these applied voltages to enhance the corrosion of Ti-6Al-4V inside SBF. Because of good corrosion parameters values for the deposition at 9 volt compare with other values, the applied voltage between cathode and anode will be constant at this value for following experiments.

\section{2-Results and discussion of optimumPH value:}

\section{C- Structure characterization:}

Figure4 shows the XRD pattern of the specimen after electrochemical deposition and treatment in $\mathrm{NaOH}$ solution for uncoated and coated samples at various PH values. 


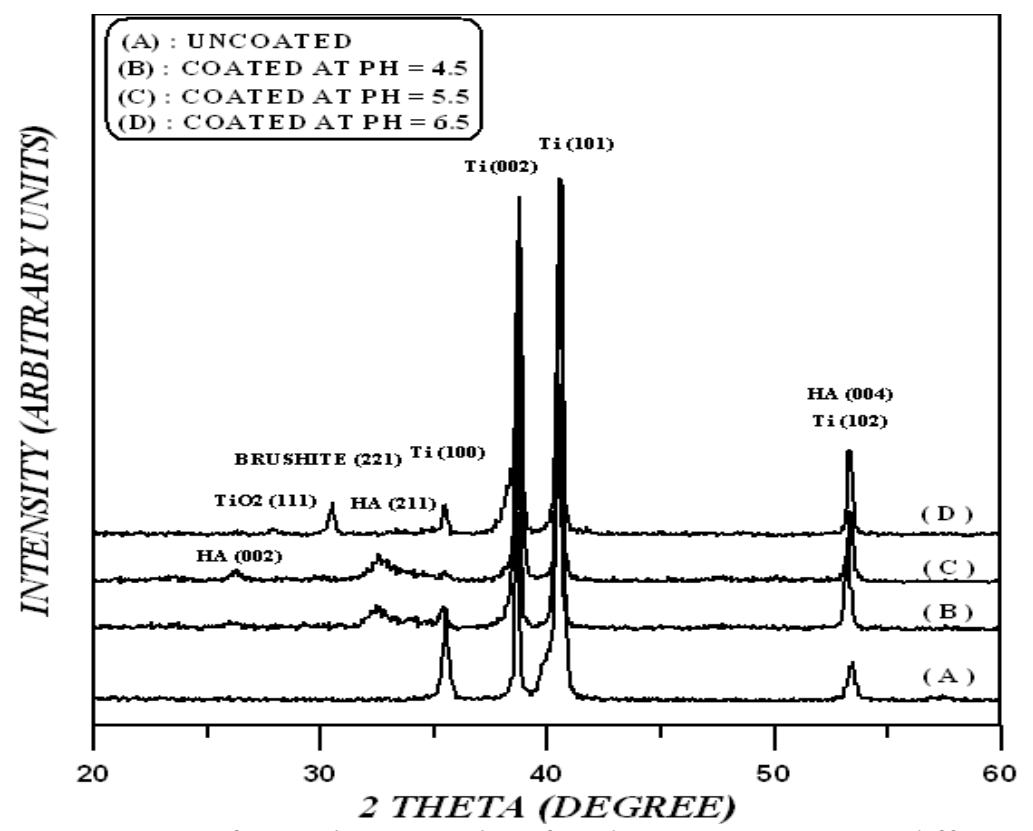

Figure (4) XRD patterns of Ti-6Al-4V samples after deposition process at different $P H$ values of ECHS.

Figure4 shows the appearance of first HA peak (211) when $\mathrm{PH}=4.5$ and the second one (002) appeared at $\mathrm{PH}=5.5$; but they disappeared at $\mathrm{PH}=6.5$. Instead of HA peaks Brushite peak (221) appears; so it can be concluded that at $\mathrm{PH}=6.5$ and applied voltage $=9 \mathrm{~V}$ incomplete transformation to HA Phase was obtained. This result disagree with L.Medevecky ${ }^{[1]}$ who referred to the transformation of Brushite to hydroxyapatite by using the hydrothermal method at highPH values.

Also in this pattern $\mathrm{TiO}_{2}$ peak (111) exists when $\mathrm{PH}=6.5$, this refers to production of strong oxidation agent at high $\mathrm{PH}$ values.

\section{D- Corrosion studies:}

\section{I-Open circuit potential-time measurements}

All curves in Figure 5 have the same behavior; they reach steady potentials afterapproximately same times. As can be seen, potential shifts with time in the more electropositive direction of potential indicating spontaneous passivation, possibly due to continuous healing and growth of a certain barrier film on the electrode surface ${ }^{[12]}$.Also, from this figure it can be concluded that; a coated sample at $\mathrm{PH}=4.5$ has more passive protection layer compared with other samples.

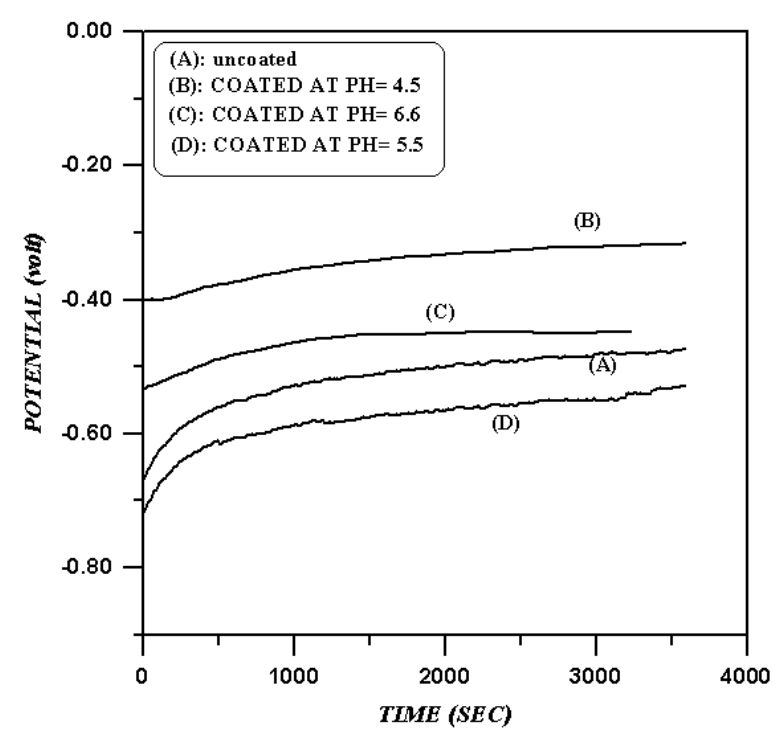

Figure (5)Open circuit potential in SBF solution versus time plots for a uncoated and HA coated Ti-6Al-4Vat various $\mathrm{PH}$. 
II-Potentiodynamic polarisation studies

Figure 6 and Table 3 illustrate the improvement of corrosion rate and corrosion current with increasing PH values until $\mathrm{PH}=6.5$. Corrosin parameters downfall at this value may due to the formation of Brushite Phase as XRD pattern (Figure 6) confirmed. $\mathrm{TiO}_{2}$ protective layer, which has small (111) peak in XRD pattern, did not work properly as corrosion resistance layer when it appeared at $\mathrm{PH}=6.5$.

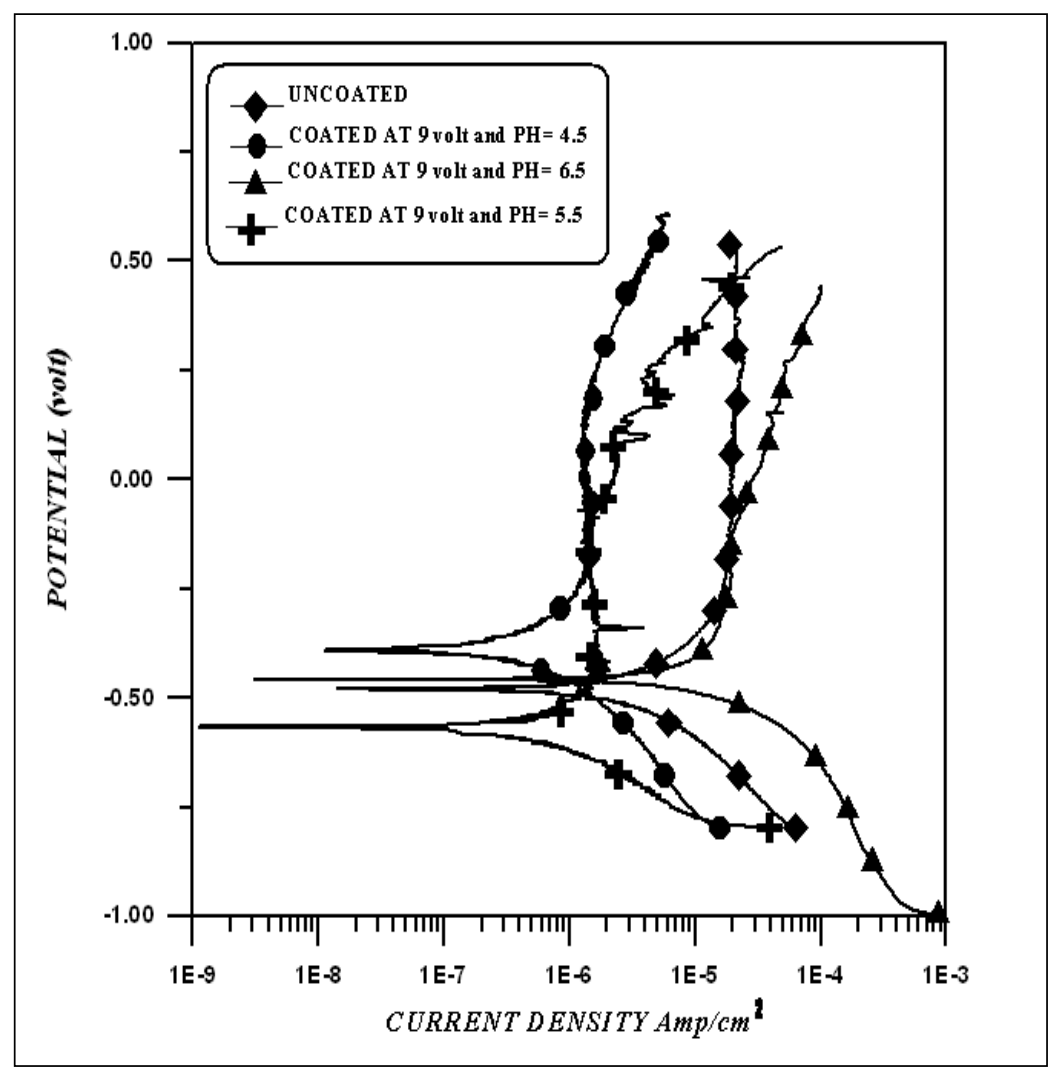

Figure (6) Tafel plots for uncoated and coated Ti-6Al-4V alloy with various $\mathrm{PH}$ values.

Table 3Electrochemical parameters for uncoated and coated Ti alloy atvarious PHvalues.

\begin{tabular}{|c|c|c|c|}
\hline PH values & $\begin{array}{c}\text { E }_{\text {CORR. }} \\
(\text { volt })\end{array}$ & $\begin{array}{c}I_{\text {CORR. }} \\
(\mu \mathrm{A})\end{array}$ & $\begin{array}{c}\text { Corrosion Rate } \\
\left(\mathrm{mmpy}^{*} \mathbf{1 0}^{-3}\right.\end{array}$ \\
\hline uncoated & -0.482 & 1.128 & 10.23 \\
\hline 4.5 & -0.391 & $\mathbf{0 . 4 3 7 8}$ & 3.971 \\
\hline 5.5 & -0.571 & $\mathbf{0 . 1 4 6 5}$ & 1.329 \\
\hline 6.5 & -0.451 & 4.717 & 42.79 \\
\hline
\end{tabular}

A good values for passive current andcorrosion potential $\left(\mathrm{E}_{\mathrm{CORR}}\right)$ for deposition at $\mathrm{PH}=4.5$ were the reason behind choosing this value as optimum $\mathrm{PH}$ value.

3-Results and discussion of choosing optimumtemperature degree:

E- Structure characterization: 


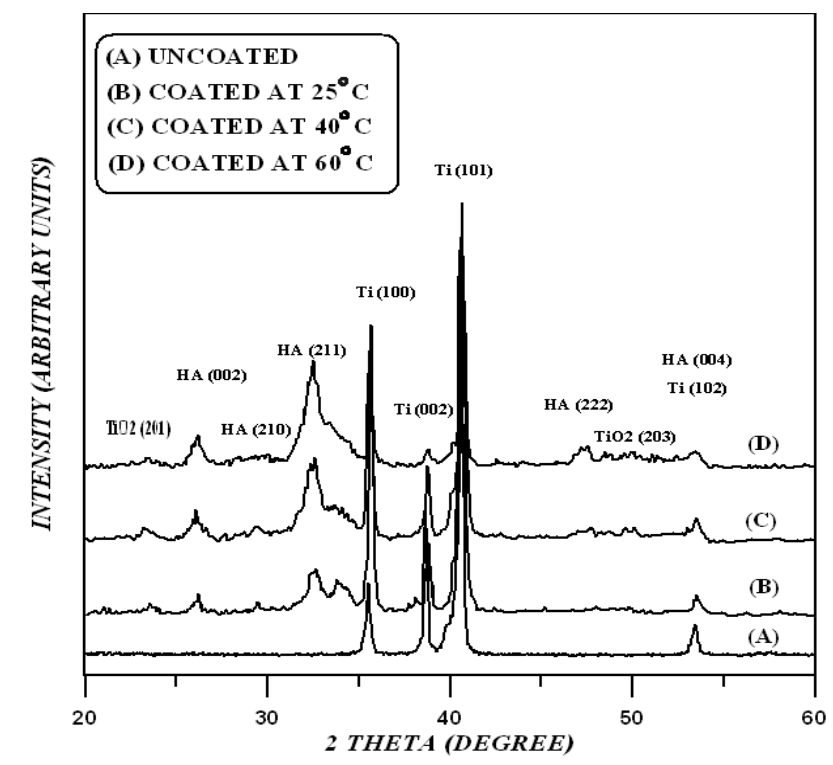

Figure (7) XRD patterns of Ti-6Al-4V samples after deposition process at different chemical solution temperatures.

Figure7 shows XRD patterns of uncoated and coated samples at different ECHS temperatures. There is coexistence of $\mathrm{HA}$ and $\mathrm{TiO}_{2}$ phases after raising the temperature of ECHS above room temperature. $\mathrm{TiO}_{2} \mathrm{Phase}$ existence refers to incomplete coverage of coating layer on Ti-alloy or it refers to thin HA layer. Intensities of HA(211) andHA(002)peaks and their broad increase with temperature increasing. These peaks have higher full width at half maximum (FWHM) compare with those values in Figure1 and Figure 4,this refers to lower grain sizes of HA for these orientations. The differences between XRD in Figure 7 with that of Figures 1 and 4 are: appearance of new HA peaks like (222) and (210) and $\mathrm{TiO}_{2}$ peaks like (203) and (241).Also, there is no trace for BrushitePhase existence.

\section{F- Corrosion studies:}

I-Open circuit potential-time measurements:

Except the deposited layer at $40^{\circ} \mathrm{C}$,all other samples have increasing potential in the positive direction, see figure 8 .This indicates to the formation of a passive filmensuring the long term application. A steady state potential indicates that the film remains intact and protective. A drop of potential in the negative direction for deposited layer at $40^{\circ} \mathrm{C}$ indicates breaks in the film, dissolution of the film, or no film formation. For Ti-6Al-4V coated at $25^{\circ} \mathrm{C}$, the OCP is higher than that of uncoated Ti-6Al-4V because the passive layer is thicker and because of the inert HA coating.

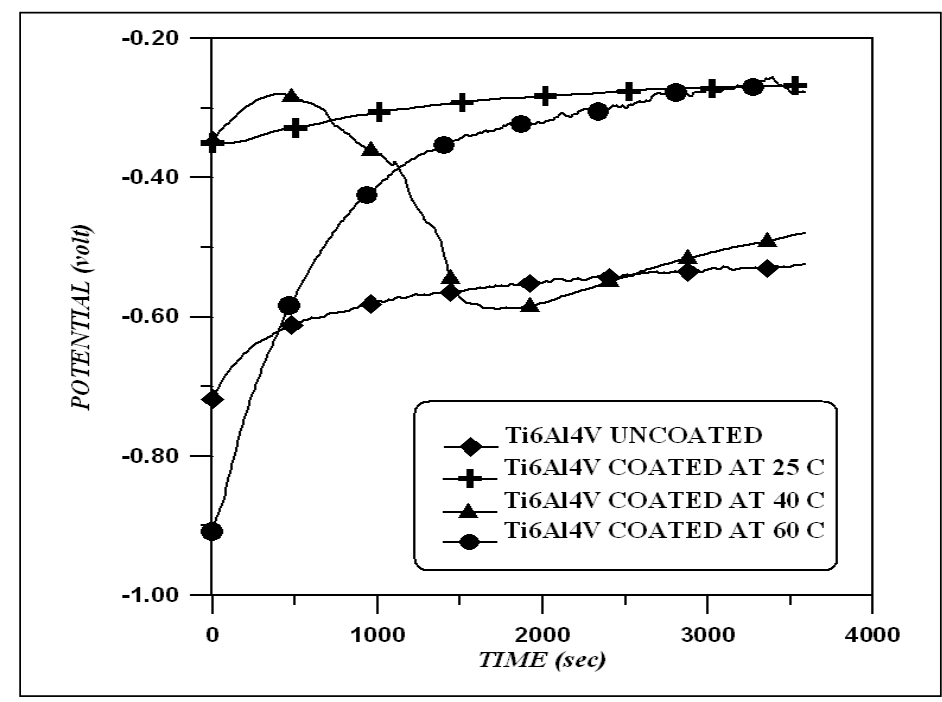

Figure (8) Open circuit potential in SBF solution versus time plots for a uncoated and HA coated Ti-6Al4Vdeposited at various temperatures. 
II-Potentiodynamic polarisation studies

Figure 9 illustrates the decreasing of passive currents for all samples compared with uncoated alloy, but deposited layer at $40^{\circ} \mathrm{C}$ has the minimum passive current. This result refers to creating a good protection layer at $40^{\circ} \mathrm{C}$. Corrosion parameters listed at Table 4 shows decreasing Corrosion currents and Corrosion rates for deposited layers at $20^{\circ}$ and $40^{\circ} \mathrm{C}$ respectively, but these two parameters increase when deposition temperature became $60^{\circ} \mathrm{C}$.

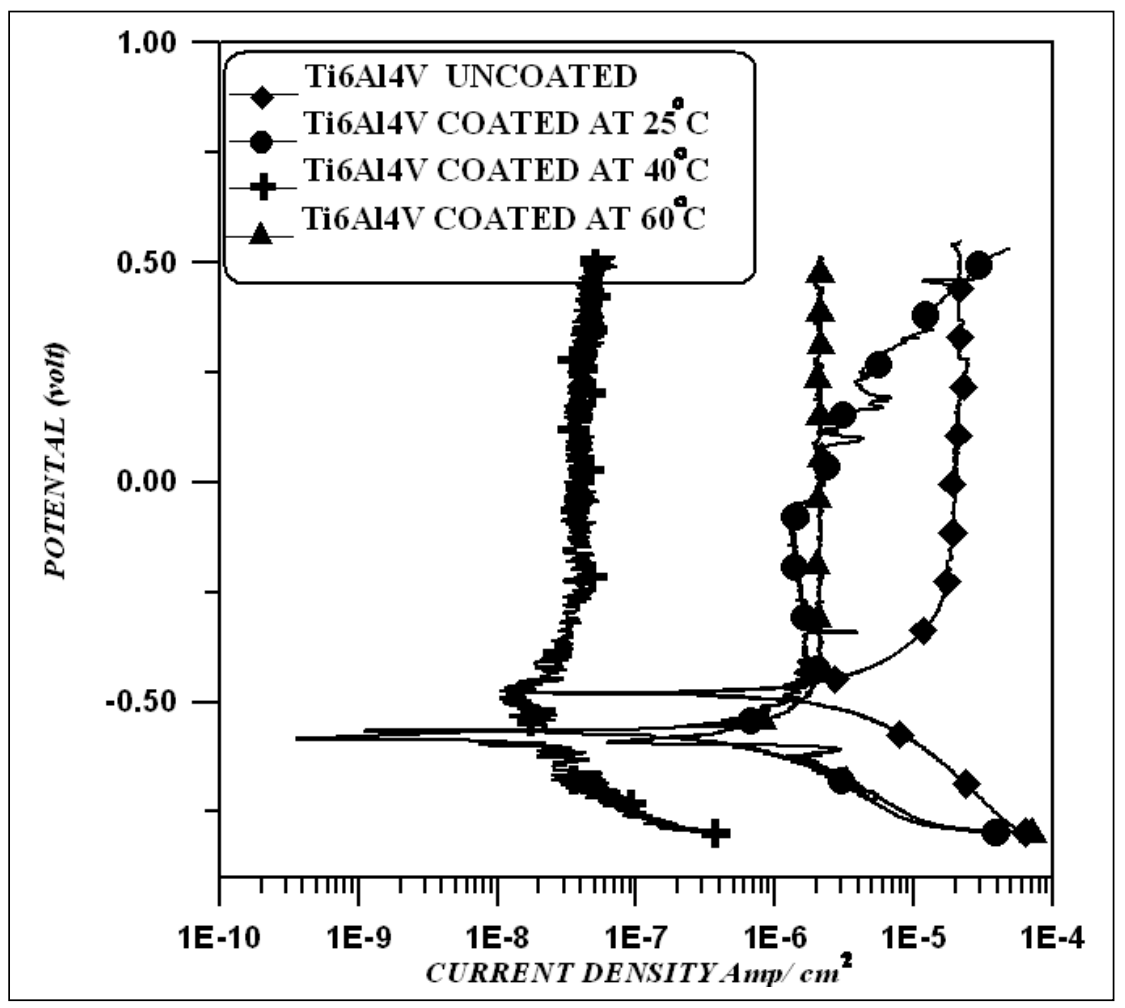

Figure (9) Tafel plots for uncoated and coated Ti-6Al-4V alloy with various chemical solution temperature.

Table 4Electrochemical parameters for uncoated and coated Ti alloy atvarious temperature.

\begin{tabular}{|c|c|c|c|}
\hline $\begin{array}{c}\text { Temp. of deposition } \\
\text { solution }\left({ }^{\circ} \mathbf{C}\right)\end{array}$ & $\begin{array}{c}\mathbf{E}_{\text {CORR. }} \\
(\text { volt })\end{array}$ & $\begin{array}{c}\mathbf{I}_{\text {CORR. }} \\
(\mu \mathrm{A})\end{array}$ & $\begin{array}{c}\text { Corrosion Rate } \\
(\mathbf{m m p y}) * 10^{-3}\end{array}$ \\
\hline Uncoated & $\mathbf{- 0 . 4 8 2}$ & $\mathbf{1 . 1 2 8}$ & $\mathbf{1 0 . 2 3}$ \\
\hline 25 & $\mathbf{- 0 . 5 7 1}$ & $\mathbf{0 . 1 4 6 5}$ & $\mathbf{1 . 3 2 9}$ \\
\hline $\mathbf{4 0}$ & $\mathbf{- 0 . 5 7 8}$ & $\mathbf{0 . 0 1 0 3 5}$ & $\mathbf{0 . 9 3 9}$ \\
\hline 60 & $-\mathbf{0 . 5 8 7}$ & $\mathbf{0 . 2 1 0 2}$ & $\mathbf{1 . 9 0 6}$ \\
\hline
\end{tabular}

4-Results and discussion of choosing optimum deposition time:

\section{G- Structure characterization:}

Figure10shows the high intensities of $\mathrm{HA}(002)$ peaks compared with that at previous XRD patterns,also this figure illustrates the high intensities of $\mathrm{Ti}(100)$ peaks compared with $\mathrm{Ti}(002)$ peaks, the reverse occurred at figures 1 and 4. $\mathrm{TiO}_{2}(601), \mathrm{TiO}_{2}(400)$ and $\mathrm{HA}(213)$ peaks did not appear at all XRDpatterns except at figure

10.The unique structure variationsof figure 10 refer to big role of changing deposit time. 


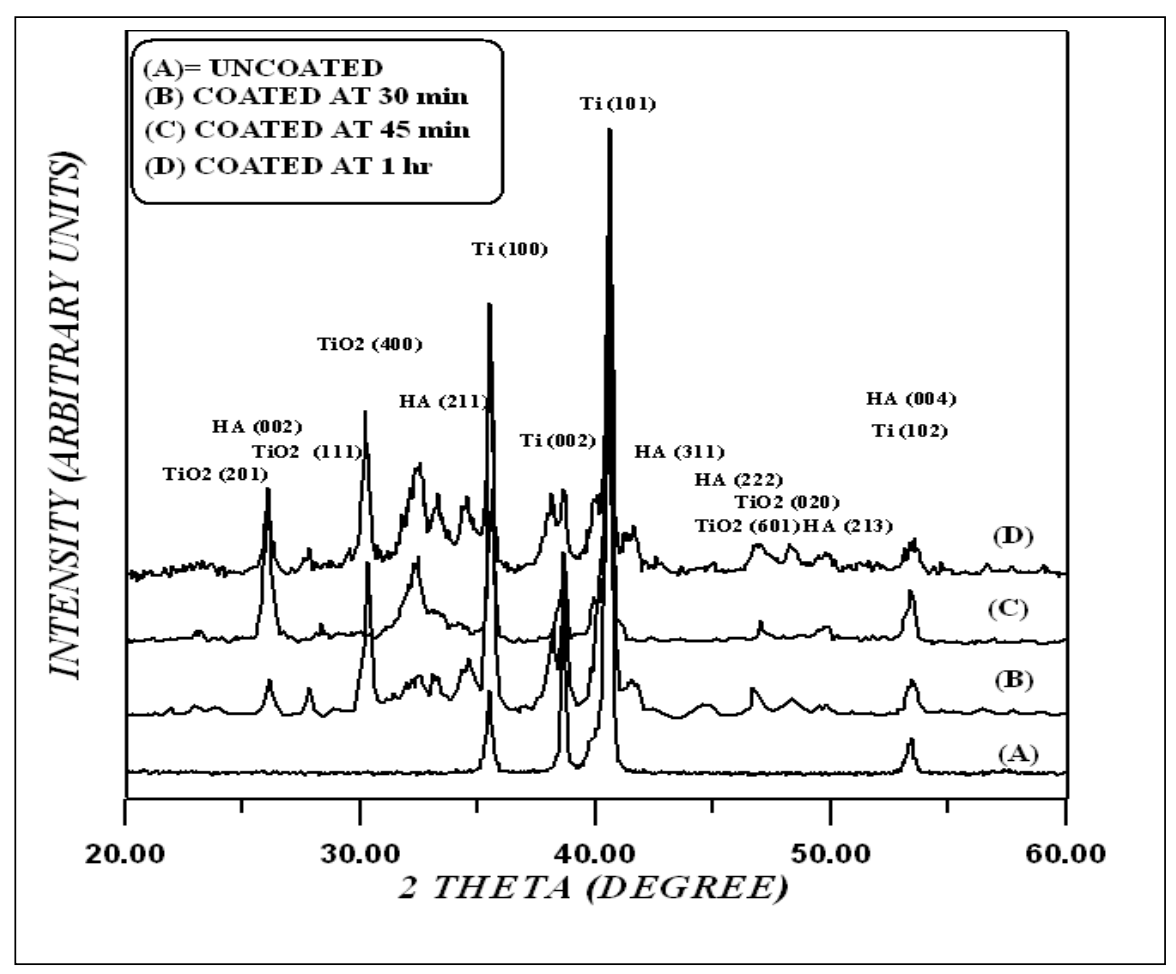

Figure (10) XRD patterns of Ti-6Al-4V samples after deposition process at different deposition times.

\section{H- Corrosion studies:}

\section{I-Open circuit potential-time measurements:}

Passivity in body fluids is the major characteristics of surgical alloys. The stability of passive condition of the coated Ti-6Al-4V alloy at different deposition periods is illustrated by the potential-time curves in Figure11.It can be clearly seen that all the curves are similar and run nearly parallel to each other in all conditions. It is observed that there is an initial shift of potential in the active direction followed by a continuous rise in potential towards noble direction to attain finally the steady state potentials. These results revealed a presence of competition between film dissolution and film formation, which end by self-healing of surface film.

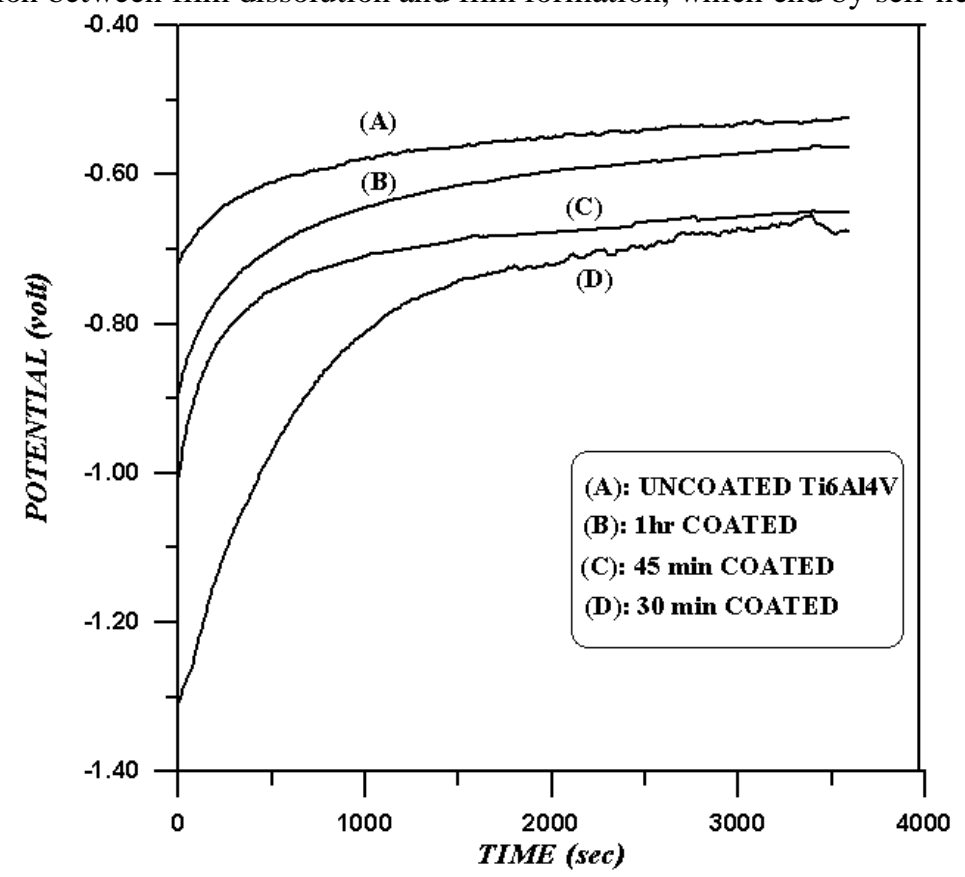

Figure (11)Open circuit potential in SBF solution versus time plots for a uncoated and HA coated Ti-6Al4Vdeposited at various deposition times. 
II-Potentiodynamic polarisation studies

Figure 12 shows that all coated samples have passive current less than that of uncoated one, this to make a sign to build a passive layer protect on Ti-6Al-4V alloy during all deposition times. Table 5 refer to the superiority of deposition time at 30 minute on other deposition times in getting optimum corrosion current, passive current and corrosion rate. Longer time other than 30 minute may produce local defects and cracks which play a bad effect on corrosion resistance of deposited layers.

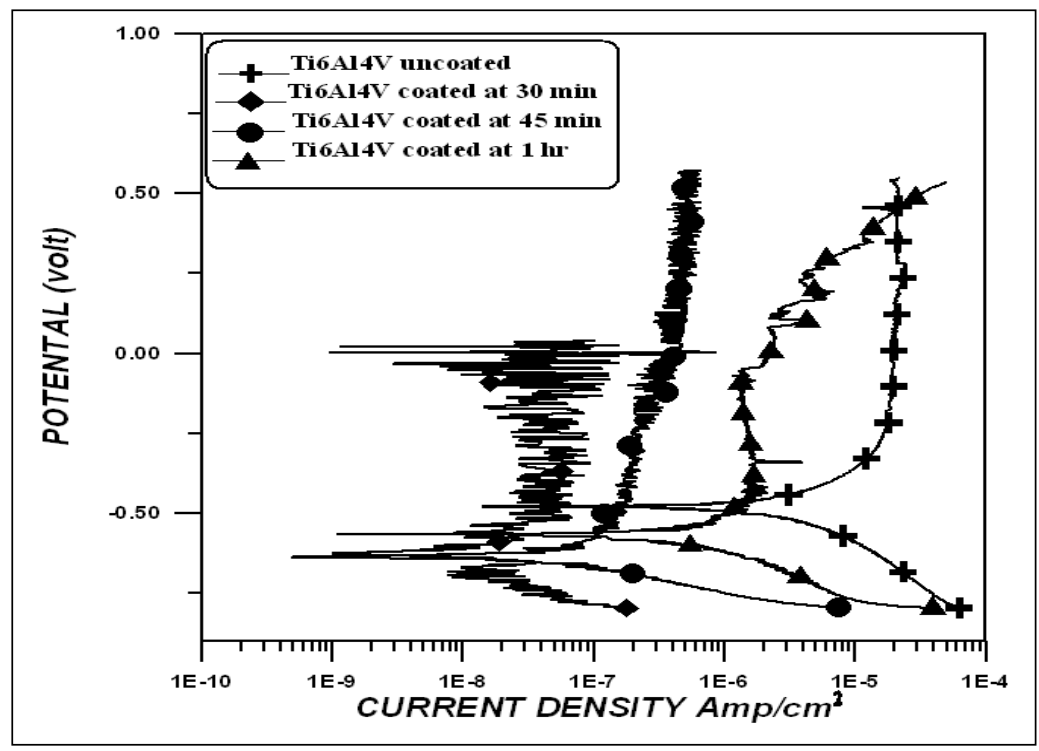

Figure (12) Tafel plots for uncoated and coated Ti-6Al-4V alloy with various deposition time.

Table 5Electrochemical parameters for uncoated and coated Ti alloy atvarious deposition time.

\begin{tabular}{|c|c|c|c|}
\hline $\begin{array}{c}\text { Deposition time } \\
(\text { min })\end{array}$ & $\begin{array}{c}\mathbf{E}_{\text {CORR. }} \\
(\text { volt })\end{array}$ & $\begin{array}{c}\text { I }_{\text {CORR. }} \\
(\boldsymbol{\mu A})\end{array}$ & $\begin{array}{c}\text { Corrosion Rate } \\
(\mathbf{m m p y}) * 10^{-3}\end{array}$ \\
\hline uncoated & $\mathbf{- 0 . 4 8 2}$ & $\mathbf{1 . 1 2 8}$ & $\mathbf{1 0 . 2 3}$ \\
\hline 30 & $\mathbf{- 0 . 6 2 4}$ & $\mathbf{0 . 0 0 5 7 7}$ & $\mathbf{0 . 0 5 2 5}$ \\
\hline 45 & $\mathbf{- 0 . 6 3 5}$ & $\mathbf{0 . 0 3 7 7}$ & $\mathbf{0 . 2 9 0 6}$ \\
\hline 60 & $\mathbf{- 0 . 5 7 1}$ & $\mathbf{0 . 1 4 6 5}$ & $\mathbf{1 . 3 2 9}$ \\
\hline
\end{tabular}

Figure 13 shows SEM image of deposited specimen at the following conditions: applied voltage $9 \mathrm{v}, \mathrm{Ph}=5.5$,time $=45$ minute and deposition time 1 hour. This figure illustrates Irregularity of HA particles
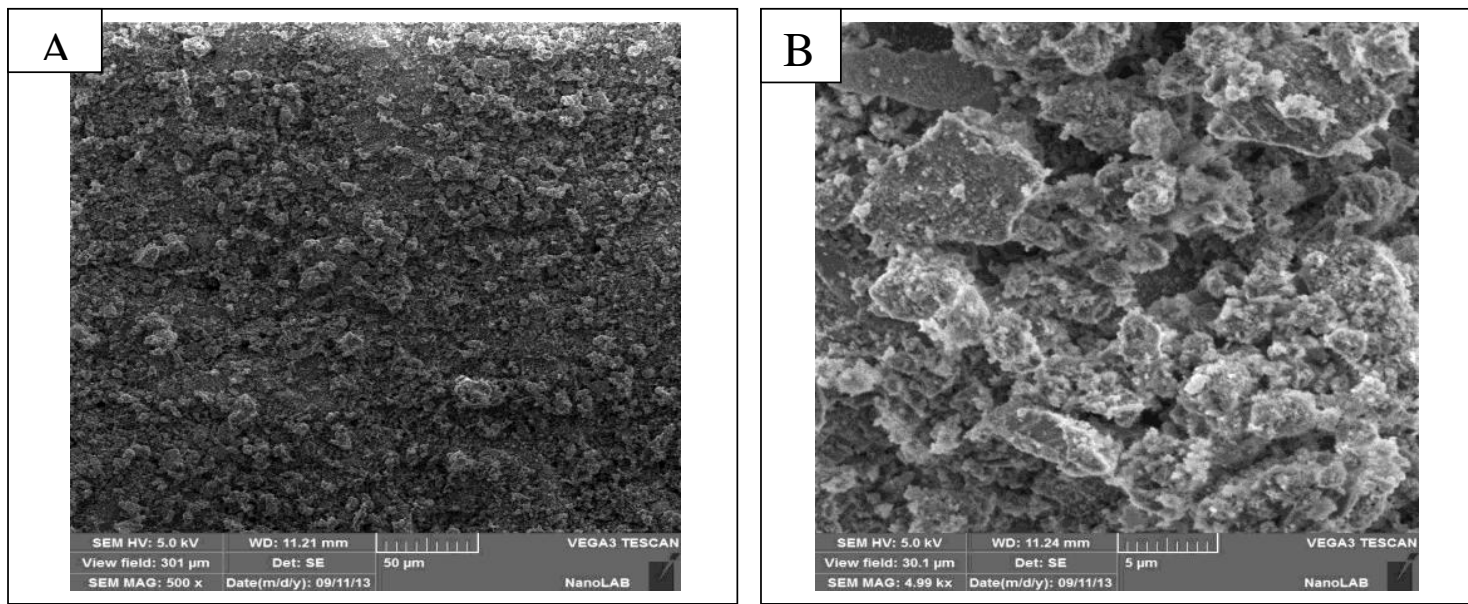

Figure (13) A-SEM image of HA layer on Ti-6Al-4V. B- Irregular HA particles.

and a relatively high roughness. Also these two images refer to the absence of any cracks when HA was deposited at these conditions,suggesting that there was no significant shrinkage of thecoating. This result confirms that; the electro deposition processing approach is very convenient in terms ofobtaining dense samples. 


\section{CONCLUSIONS}

The deposition parameters play key roles in the microstructure control of the products and their corrosion resistance.In our experiments, optimum corrosion parameters were obtained when applied voltage 9 volt,deposited time 30 minute, $\mathrm{PH}$ value 5.5 and solution temperature $25^{\circ} \mathrm{C}$.

\section{REFERENCES}

[1]- L. Medvecký and R. Štulajterová .Characterization of bilayered Brushite / Hydroxyapatite coating on titanium substrate.Powder Metallurgy Progress.2008;8(1),35-45.

[2] W.Shi,A. Kamya,J. Zhu, A. Watazu. Properties of titanium biomaterial fabricated By sinter bonding of Titanium/Hydroxyapatite composite surface coated layer to pure bulkTitanium.Materials science and engineering A337.2002;104-109.

[3]. C. K. Wang, J. H. Chern Lin.Pulse Laser Deposition of Hydroxyapatite. Biomaterials. 1997;18,1338-1331. [4]- C.Wang, J. Mo, W.Cheng and R.Zhang.Thick hydroxyapatite coatings by electrophoretic deposition.Materials Letters.2002;57,105-99.

[5]- M. C. Kue and S. K. Yen. The process of electrochemical deposition hydroxyapatite on biomedical Titanium at room temperature. Materials Science and engineeringC.2002;20,160-153.

[6]- M. Saremi and B. Mottaghi Golshan.Electro deposition of nano size hydroxyapatite coating on Ti alloy. Iranian Journal of Materials Science and Engineering.2006;3(3-4).

[7]- H. Wang , N. Eliaz and Linn W. Hobbs. The nanostructure of an electrochemically deposited hydroxyapatite coating. Materials Letters.2011;65,2455-2457.

[8]- Z. Yuan-yuan, T. Jie, P. Ying-chun, W. Wei and W. Tao.Electrochemical deposition of hydroxyapatite coatings on titanium. Trans.Nonferrous Met.Soc.China.2006;16,633-637.

[9]-H. LY, X. KW and L.J. A study of the process and kinetics of electrochemical deposition and hydrothermal synthesis of hydroxyapatite coatings. Materials in Medicine, 2000;11(11), 667-673.

[10]- M. Shirkhanzadeh.Direct formation of nanophase hydroxyapatite on cathodically polarized electrodes. Journal of materials science: Materials in medicine1998;9,67-72

[11]-N. Eliaz, T. M. Sridhar, U. Kamachi Mudali and Baldev Raj.Electrochemical and electrophoretic deposition of hydroxyapatite for orthopaedic applications. Surface Engineering. 2005;21(3).

[12]-F. El-Taib Heakal,M.M.Henfy, A.M. Abd El-Tawab, Electrochemical Behavior of Titanium in Saline Media, Containing alga Dunaliella Salina and Its Secretions. Int. J. Electrochem. Sci..2013;8, 4610 - 4630. 